\title{
Congestion charge, air pollution and children's school attendance: benefitting the poor
}

\author{
Risto Conte Keivabu \\ Tobias Rüttenauer \\ European University Institute Nuffield College, University of Oxford \\ risto.conte@eui.eu_tobias.ruttenauer@nuffield.ox.ax.uk
}

\begin{abstract}
Air pollution negatively affects individuals' health and human capital accumulation. For example, students school performance is hampered by air pollution as it decreases cognitive abilities and increases absences. Moreover, low-income students are the most exposed and vulnerable to the negative effects of air pollution lacking protective resources and suffering from pre-existing health conditions. Here, we inquire how more stringent traffic regulations implemented in Central London from late 2015 affected pollution levels and school absences. First, we observe a substantive decrease in pollution in the area affected by the regulations from 2016. Secondly, we use a Difference in Difference approach to estimate the causal effect of the policy on air pollution and school absences. For all schools combined, findings do not show any substantive improvement in attendance. However, when looking at the heterogeneous effects of the policy, we observe a larger decrease in absences for Low socioeconomic status (SES) students. Moreover, we find a positive spillover effect for schools just outside the area targeted by the policy. Consequently, the findings highlight the efficacy of environmental policy in diminishing pollution levels and to benefit the poor.
\end{abstract}




\section{Introduction}

The exposure to air pollution has not only been linked to poor health (Currie, 2013; Diane \& Schwandt, 2019; Kravitz-Wirtz et al. 2018) but also to the educational performance of children (Amanzadeh, Vesal \& Ardestani, 2020; Buka, Koranteng, Osornio-Vargas, 2005; David, Ebenstein, Lavy \& Roth,2016; Heissel, Persicon \& Simon, 2019; Persico, 2020). Recent research shows, for instance, that early-life exposure to industrial emissions can cause long-lasting educational disadvantages (Colmer and Voorheis, 2020). One pathway of the negative effect of air pollution on the educational performance is an increase in school absences. Exposure to air pollution has been shown to increase absences due to poor health, or avoidance behaviour skipping classes during polluted days (Currie et al., 2009). This pathway of educational consequences might also reinforce more general inequalities in the society, as some individuals are more exposed and more vulnerable than others to air pollution and its negative effect on human capital accumulation and later life outcomes (Manduca \& Sampson 2019; Manduca \& Sampson, 2021).

Socioeconomic status is a main characteristic affecting disparities in exposure and vulnerability to air pollution. Inequalities in exposure are well known in the literature and show that air pollution is more concentrated in areas inhabited by minorities and low-income individuals (Colmer et al., 2020; Grineski \& Collins, 2018; Rüttenauer, 2018). Disparities in vulnerability to air pollution have been documented by Kravitz-Wirtz et al. 2018, showing that mainly inhabitants of poor neighbourhoods experience negative health effects when exposed to nitrogen dioxides and particulate matter. Similarly, excess mortality has been linked with exposure to PM10 only for low SES individuals in Latium, Italy (Forastiere et al., 2007).

In this study, we use the example of Greater London to investigate three main research questions. First, we explore how effective environmental policies targeting urban traffic are in improving air quality. Secondly, we inquire the health benefits of decreased air pollution, focusing on children's school absences. Finally, we ask if school SES stratifies the decrease in air pollution and the effect on school absences inspired by previous work showing the existence of disparities in exposure and vulnerabilities.

London's poor air quality is a risk for the citizen's health and wellbeing. Most notably, several schools are still exposed to pollution levels above the World Health Organization guidelines ${ }^{1}$ and children continue to suffer from negative health effects, despite the introduction of traffic regulations in 2003 (Green et al., 2020; Mudway et al., 2019; Wood et al., 2015). However, starting in September 2015, tighter rules have been implemented in the London Congestion Charge Zone (CCZ) leading to

\footnotetext{
${ }^{1}$ Extensive evidence on the exposure to air pollution has been collected by report promoted by the Mayor of London and can be found at: https://www.london.gov.uk/press-releases/mayoral/hundreds-of-schools-exceed-air-quality-limits .
} 
the implementation of an Ultra-Low Emission Zone (ULEZ) in 2019². The set of policies implemented from 2015 in the CCZ remarkably improved air quality in several neighbourhoods raising questions on the possible health benefits for school children. Consequently, we combined precise information on air pollution and school absences in the Greater London area from 2007 to 2019. Moreover, to answer our research question, we used a Difference in Differences approach to causally estimate the effect of the more stringent regulation on air quality and school absences.

The paper contributes to the literature on the link between air pollution, children health and socioeconomic disparities in four main ways. First, best to our knowledge, this is the first study inquiring how environmental policies targeted on traffic affect school absences. Secondly, we show how environmental policies targeting traffic can effectively improve air quality. Thirdly, we provide novel evidence on the existence of SES disparities in exposure, vulnerability and responsiveness to policies targeting air pollution. Finally, in our supplementary analysis, we expose the existence of positive spill-over effects of the CCZ on air pollution and school absences.

The article is structured as follows. In the next section we describe how air pollution affects school absences and why it is more critical for low socio-economic groups. Moreover, we illustrate why the regulations implemented in London's CCZ from late 2015 and not before improved air quality. We then proceed outlining the data, variables, and identification strategy. In the results section, we report the findings on the pooled sample, the stratified effects on air pollution, absences and supplementary analysis. Lastly, we discuss the relevance of the results, limitations, and further venues of research.

\section{Air pollution, socioeconomic status \& educational inequalities}

Air pollution is a major threat for children's health having direct consequences on their school performance. Air pollution has been found to have a short-term negative effect on cognitive abilities decreasing test performance (Amanzadeh, Vesal \& Ardestani, 2020; Grineski, Collins \& Adkins, 2020; Ebenstein, Lavy \& Roth, 2016). However, another pathway by which air pollution might affect school outcomes is increasing absences. For example, the seminal study by Currie et al. (2009) has shown that higher levels of pollution increased school absences in Texas, in the US. What appears to explain an increase in school absences with higher levels of air pollution is the aggravation of cardiorespiratory conditions in children. For example, individuals suffering from chronic obstructive pulmonary disease, allergic symptoms, asthma or rhinitis are ill prepared to affront high levels of air pollutants (Alotaibi et al., 2019; Jiang, Mei, Feng, 2016; Mudway et al., 2019; Wood et al., 2015). A

\footnotetext{
${ }^{2}$ The ULEZ has been officially established in 2019 and will be enlarged to a larger area in October 2021.
} 
competing explanation is based on behaviorial responses to air pollution, whereby individuals prefer to avoid exposure to air pollution by staying at home when air quality is low (Yoo, 2021).

Socioeconomic status has been found to stratify the effects of air pollution on individual's health. The likely pathways explaining these differences are related to disparities in exposure and vulnerability. Previous studies have found low SES neighborhoods and ethnic minorities to be more exposed to air pollutants (Colmer et al., 2020; Rüttenauer, 2018). A similar pattern has been found when inquiring exposure at school premises in the USA (Grineski \& Collins, 2018). However, even when exposed to the same amount of pollution, households differ in their vulnerability to these pollutants (Forastiere et al., 2007; Liu et al., 2021). There are three possible mechanisms explaining differences in the risk by SES. Firstly, the prevalence of cardio-respiratory conditions is more common among poor children. For example, there is a higher prevalence of asthma among low SES children (Gong et al., 2014). Secondly, high SES parents are better able to compensate for the negative events that might affect their children (Bernardi, 2014; Torche, 2018). For example, high SES parents are more likely to seek primary care for their children and this is true also when considering respiratory diseases (Cope, Ungar \& Glazier, 2008; Stingone \& Claudio, 2006). In addition, parents might proactively reduce children exposure to air pollutants during highly polluted days, keeping them home as they are more wary of air quality (Currie et al., 2009; Guo et al., 2016). Thirdly, high SES households may have better means to shield themselves from high levels of out-door emission (Diekmann et al. 2020). Given the same level of out-door traffic pollution, high SES households are likely to experience lower indoor exposure because of higher window quality or more expensive flats pointing into less polluted directions of a building, thereby reducing the actual inhalation exposure to out-door pollution.

\section{London, traffic regulation and air pollution}

Traffic is the main contributor to air pollution in London and several policies have been implemented to improve air quality. In 2003, the first Congestion Charge Zone (CCZ) has been established determining a fee of $5 £$ to access the area of Central London. This policy has been revised over time by either raising the price, enlarging the area or tightening the emission criteria for cars entering the $\mathrm{CCZ}^{3}$.

However, did the policies effectively reduce air pollution and improve the population's life outcomes? Results on the improvements in air quality have been mixed. One study has explored the effectiveness of the establishment of the CCZ in 2003 showing only a slight decrease in PM10 and Carbon Oxide (CO) but an increase in Nitrogen Dioxide (NO2) (Green et al., 2020). The authors

\footnotetext{
${ }^{3}$ A summative list of the policies is present in the Appendix in TableA1.
} 
explain the contrasting evidence by a potential substitution effect: the enhanced presence of public transportation or diesel engine cars might have replaced previous petrol vehicles increasing the level of NO2 in the area. Similar results have been found when inquiring the Western Extension of the congestion charge from 2007 to 2011 (Li \& Ding, 2020). Moreover, there is evidence of an increase in inequalities in exposure to traffic pollutants in the UK (Barnes, Chatterton \& Longhurst, 2019). Considering the health benefits derived from the policy, two studies inquired how children respiratory health responded to the implementation of the CCZ (Mudway et al., 2019; Wood et al., 2015). Both studies do not show any improvement in children's respiratory health. Overall, all the studies on London's CCZ argued for stricter traffic regulations as necessary condition to enhance air quality and public health.

Tighter rules regulating the emission of vehicles circulating in this area have been implemented from September 2015 on. These rules heightened the standards of Diesel cars entering the area to the Euro 6 level. Similarly, cleaner public transportation has been introduced. Early results of a report commissioned by the Mayor of London, showed major improvements in air quality from 2016 to 2020 in several neighbourhoods of the city. ${ }^{4}$

In Figure 1, we plot the trends from 2007 to 2019 in nitrogen dioxide (NO2), particulate matter 10 (PM10) and particulate matter 2.5 (PM2.5), and Benzene at schools in the CCZ and non-CCZ. Moreover, the dashed red line indicates the year 2015 to demarcate the start of tighter rules. Overall, we observe a higher level of toxic pollutants in the $\mathrm{CCZ}$ area. However, there is a substantial decrease in pollution over time and this decrease is stronger within the CCZ areas than outside the CCZ. Especially for PM2.5 and PM10, we observe a strong decrease from 2015 within the CCZ, which can be also observed in Figure 2. Therefore, several schools in the CCZ area, which exceeded the recommended WHO threshold ${ }^{5}$ in the earlier years, currently comply with some of these targets, raising questions on the benefits they might have experienced.

\footnotetext{
${ }^{4}$ The full report is available in the following website: https://www.london.gov.uk/sites/default/files/air_quality_in_london_2016-2020_october2020final.pdf

${ }^{5}$ The recommended limit of annual average exposure for PM 2.5 is $\overline{10} \mu \mathrm{g} / \mathrm{m} 3$, for PM10 is of $20 \mu \mathrm{g} / \mathrm{m} 3$ and for NO2 of $40 \mu \mathrm{g} / \mathrm{m} 3$.
} 
Figure 1. Change in pollution in the $\mathrm{CCZ}$ and not-CCZ before and after tighter regulations
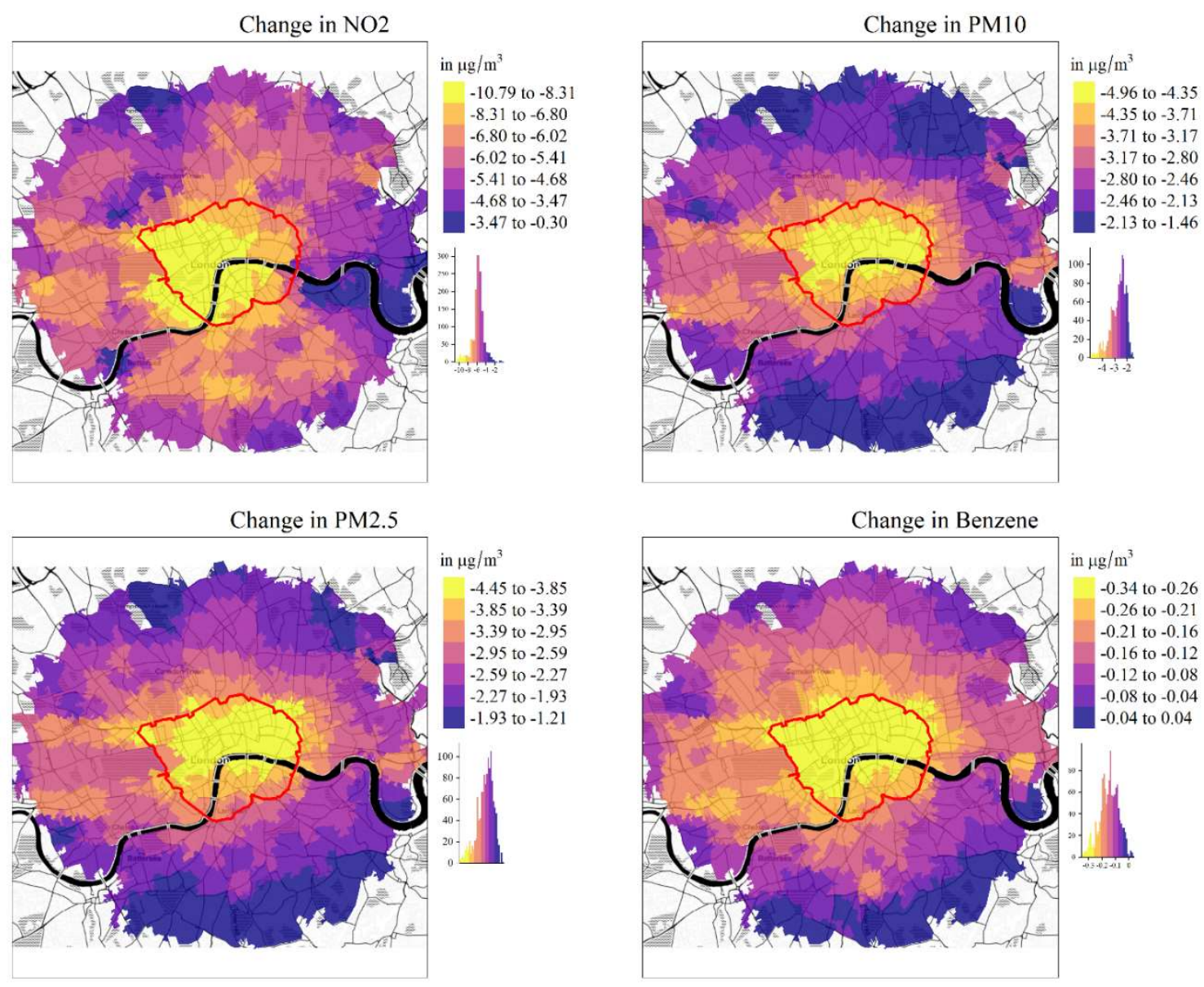

Note: Figure 1 depicts the difference in air pollution in the Greater London before (2007-2015) and after (2016-2019) tighter regulations. Lighter colours indicate stronger reductions in pollution. The red polygon marks the outline of the CCZ.

\section{Figure 2. Air Pollution over time in the $\mathrm{CCZ}$ and not-CCZ}
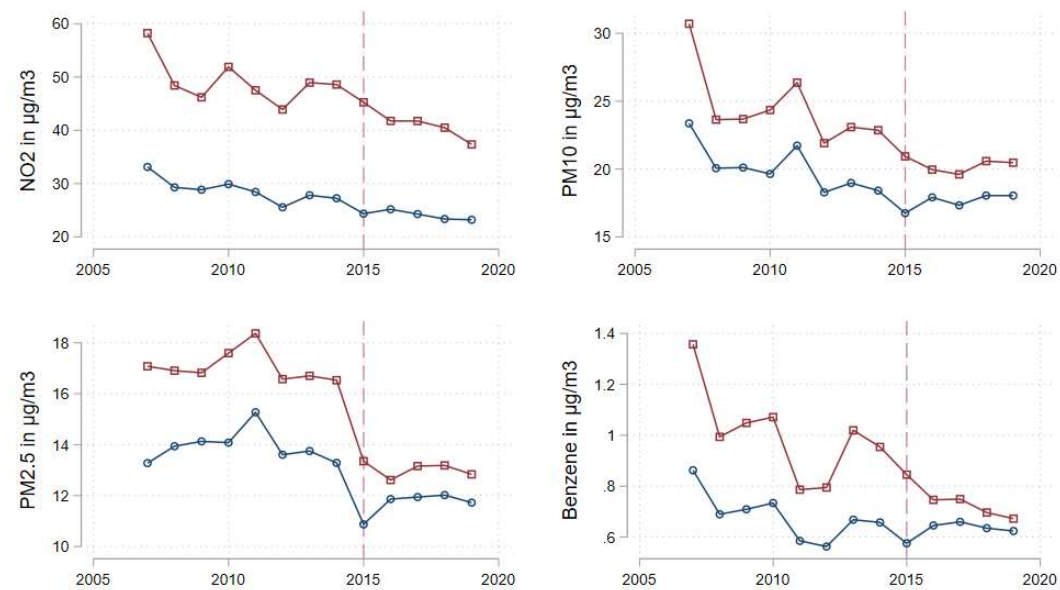

$$
\begin{aligned}
& \rightarrow \text { Not-CCZ } \\
& -\mathrm{CCZ}
\end{aligned}
$$

Note: Figure 2 displays the average level of air pollutants NO2, PM10, PM2.5 and Benzene in the CCZ and outside from 2007 to 2019. A dashed line in the year 2015 demarcates the start of tighter measures. 


\section{Data, Variables and Method}

\section{Data}

We use pollution estimates based on Defra's Modelled background pollution data (Ricardo Energy \& Environment, 2020). Defra's pollution estimates incorporate industrial point sources of emissions, household combustion estimates and road traffic emissions to estimate the annual average pollution for a $1 \mathrm{~km} \times 1 \mathrm{~km}$ grid over the UK. The modelled estimates are calculated by pollutant diffusion models, which interpolate between emission sources and calibrate the estimates based on data from local pollution measurement stations. The data include annual averages of particulate matter of different sizes (PM10, PM2.5), sulphur dioxide (SO2), Benzene, and benzene, which are all measured in $\mu \mathrm{g} / \mathrm{m}^{3}$. To allocate the pollution estimates to each school, we created a $1 \mathrm{~km}$ radius buffer around each school and assigned the pollution estimates of the $1 \mathrm{~km} \times 1 \mathrm{~km}$ grid to each school weighted by the proportionate overlap between the buffer and the pollution grids. Moreover, we used official geographical outlines of the Congestion Charge Zone (CCZ) to construct 1) a binary indicator of whether a school lies within or outside the CCZ, and 2) the distance of each outside-located school to the $\mathrm{CCZ}$.

Information on schools' absences is for students in the age range 4-18 and provided by the British Department of Education for all state funded schools in the Greater London Area ${ }^{6}$ We combined the data on school absences with the pupils' and institutional characteristics for the entire period $^{7}$. However, due to missing information the dataset results in an un-balanced panel as information is not provided for all the schools in the period of analysis ${ }^{8}$.

Variables

We focus on two sets of dependent variables. First, we investigate the log value of the pollution estimates on PM10, PM2.5, NO2 and Benzene. Secondly, we focus on school absences computed as the percentage of total sessions lost over the total number of school sessions ${ }^{9}$. We capture school socioeconomic status (SES) with a continuous variable denoting the $\%$ of students that are known to be eligible for free meals at school. We introduce control variables using dummies for quantiles of the $\%$ of students with English as a first language, \% of students of white and British origin, the \% of boys in the school and we add the rank in the Index of Multiple Deprivation (IMD)

\footnotetext{
${ }^{6}$ The dataset is freely accessible online: https://explore-education-statistics.service.gov.uk/find-statistics/pupil-absencein-schools-in-england\#dataDownloads-1

${ }^{7}$ Information on the school characteristics is available at the following website: https://www.gov.uk/government/statistics/schools-pupils-and-their-characteristics-january-2019.

${ }^{8}$ Information for the whole period of 13 years is present for $70 \%$ of the total sample of schools.

${ }^{9}$ The total number of school session is approximately 380 and corresponds to ca. 190 school days. More information on compulsory school day is provided here:

https://researchbriefings.files.parliament.uk/documents/SN07148/SN07148.pdf
} 
of the neighbourhood where the school is settled. We use dummy-coded bins of the continuous variables to account for potential nonlinearities in the effects of these controls.

\section{Method}

In the main analysis, we apply a difference-in-difference (DID) estimator to capture the causal effect of the stricter CCZ on air pollution and school absences. In the analysis, we include schools observed from 2007 to 2019 and use the CCZ policy to separate the schools into treated and control groups. Treated are the schools within the CCZ area from 2016 on and the control group is composed of the schools outside the CCZ area. We estimate the DID parameters using linear models with year and school fixed effects, and the control variables discussed above. Moreover, we apply frequency weights ${ }^{10}$ to account for yearly variations in the number of pupils in the schools. Moreover, we use two-way clustering of standard errors at the school level and at the Lower Super Output Area (LSOA) level. The two-way clustering is used to account for correlation of errors within schools and neighborhood defined using the LSOA boundaries ${ }^{11}$ (Cameron, Gelbach, Miller, 2011; Cameron \& Miller, 2015). Formally, we estimate the following model:

1) $Y_{\mathrm{st}}=\beta_{1} \mathrm{Z}_{\mathrm{s}}+\beta_{2} T_{t}+\beta_{3} \mathrm{Z}_{\mathrm{s}} \times T_{t}+\beta_{4} \mathbf{X}_{\mathrm{st}}+\alpha_{\mathrm{s}}+\alpha_{\mathrm{t}}+\varepsilon_{\mathrm{st}}$

In equation 1, the outcome $Y_{s t}$ represents air pollution/absences in school $s$ at year $t . Z_{s}$ is a binary indicator taking the value one for all schools within CCZ, zero otherwise. $T_{t}$ is a binary indicator separating schools before and after the year of implementation of the stricter policy in 2016. The interaction between $Z_{s}$ and $T_{t}$ represents the DiD estimator. $\alpha_{s}$ captures school fixed effects, and $\alpha_{t}$ year fixed effects, and $\mathbf{X}_{s t}$ is a row-vector of control variables.

This approach takes advantage of the sharp variation in air quality in the $\mathrm{CCZ}$ and outside the CCZ from 2016 to estimate the causal effect of the policy on school absences. However, this approach shares some of the disadvantages related to the use of a DiD approach. For example, the choice of a valid control group is a common challenge. Here, we run the analysis using 6 boundaries of respectively $1 \mathrm{~km}, 2 \mathrm{~km}, 3 \mathrm{~km}, 4 \mathrm{~km}, 5 \mathrm{~km}$ and $10 \mathrm{~km}$ from the CCZ (Tang, 2021). This technique allows us to compare the schools in the CCZ only with the schools outside of the CCZ but within closer boundaries. Consequently, we assume that the boundaries of the $\mathrm{CCZ}$ are drawn as good as random within these distance bounds and exploit the unexpected increase in air quality from 2015 . We should thus minimize the risk of other time-varying factors influencing our results and bring further robustness to the choice of the control group. However, these assumptions could still be violated, as

\footnotetext{
${ }^{10}$ We use frequency weights only in the analysis with absences as our main dependent variable but not in the analysis with air pollution. Results are however similar with applied weights.

${ }^{11}$ Information on the LSOA boundaries is provided here: https://data.london.gov.uk/dataset/lsoa-atlas.
} 
for instance due to the lack of parallel trends. These potential violations are tested in the robustness section.

\section{Empirical results}

In table 1, we report the summary statistics of the main variables used in the analysis separately by the schools within the $\mathrm{CCZ}$ and outside, but within the $10 \mathrm{~km}$ boundary from the CCZ. Moreover, we report the statistics for these areas before and after 2016, the stricter policy. Air pollution shows a stronger decrease in the $\mathrm{CCZ}$ as observed in Figure 1. In addition, school absences show a decrease in both areas before and after 2016 of $-0.67 \%$ in the $\mathrm{CCZ}$ and $-0.84 \%$ outside the CCZ. Overall, we can observe that there is no major change in the composition of schools in the CCZ compared to those outside.

Table 1 Summary statistics within $10 \mathrm{~km}$ before and from 2016

\begin{tabular}{|c|c|c|c|c|c|c|}
\hline & & & $\mathbf{C C Z}$ & & Not-CCZ & \\
\hline & Before & After & Difference & Before & After & Difference \\
\hline Variable & Mean & Mean & & Mean & Mean & \\
\hline Absences & 4,97 & 4,3 & $-0,67$ & 5.29 & 4.45 & $-0,84$ \\
\hline $\begin{array}{l}\% \text { Eligible to Free } \\
\text { meal }\end{array}$ & 30.34 & 23.05 & $-7,29$ & 30.76 & 21.71 & $-9,05$ \\
\hline$\%$ Mother tongue & 46.85 & 50.08 & 3,23 & 49.19 & 48.2 & $-0,99$ \\
\hline$\%$ White British & 21.54 & 19.03 & $-2,51$ & 21.54 & 19.4 & $-2,14$ \\
\hline$\%$ Boys & 50.63 & 49.51 & $-1,12$ & 51.12 & 51.1 & $-0,02$ \\
\hline IMD Rank & $9,650.49$ & $11,678.97$ & 2028,48 & $9,398.16$ & $11,485.57$ & 2087,41 \\
\hline $\mathrm{N}^{\circ}$ Pupils & 326.57 & 376.06 & 49,49 & 439.46 & 483.95 & 44,49 \\
\hline $\mathrm{N}^{\circ}$ Schools & 45 & 49 & 4,00 & 2,309 & 2,688 & 379 \\
\hline Total schoolyears & 365 & 178 & $-187,00$ & 9,050 & 4,530 & $-4,52$ \\
\hline PM10 & 24.05 & 20.15 & -3.9 & 20.99 & 18.92 & -2.07 \\
\hline PM2.5 & 16.6 & 12.95 & -3.65 & 14.39 & 12.44 & -1.95 \\
\hline NO2 & 48.68 & 40.35 & -8.33 & 32.99 & 28.32 & -4.67 \\
\hline Benzene & 0.98 & 0.72 & -0.26 & .76 & 0.7 & -0.06 \\
\hline
\end{tabular}

Note: the table represents the descriptive statistics of the main variables used in the analysis. We report the mean values in the CCZ and outside the CCZ and before and from 2016. Moreover, we compute the absolute difference for schools in the $\mathrm{CCZ}$ and outside.

In Figure 3, we report the results of the DiD analysis using the four pollutants as our outcome variables, where we vary the selection of the control group according to the distance of the schools to the CCZ. Coefficients thus tell us how much more air pollution changed in the CCZ as compared to schools outside the CCZ. The results reveal that the decrease in all pollutants was stronger within 
the $\mathrm{CCZ}$ than it was outside the $\mathrm{CCZ}$. Moreover these difference become more pronounced at a larger distance from the CCZ, except for NO2. For instance, the decrease in PM2.5 inside the CCZ was 30\% stronger than at schools within $1 \mathrm{~km}$ distance to the CCZ and $90 \%$ stronger than in schools within $10 \mathrm{~km}$ distance to the CCZ. Across our pollutants, Benzene shows the larger decrease. Overall, our results indicated the tightening of the regulation were effective in reducing the pollution at the targeted schools.

\section{Figure 3. DiD estimator for air pollution at different $\mathrm{km}$ distance}
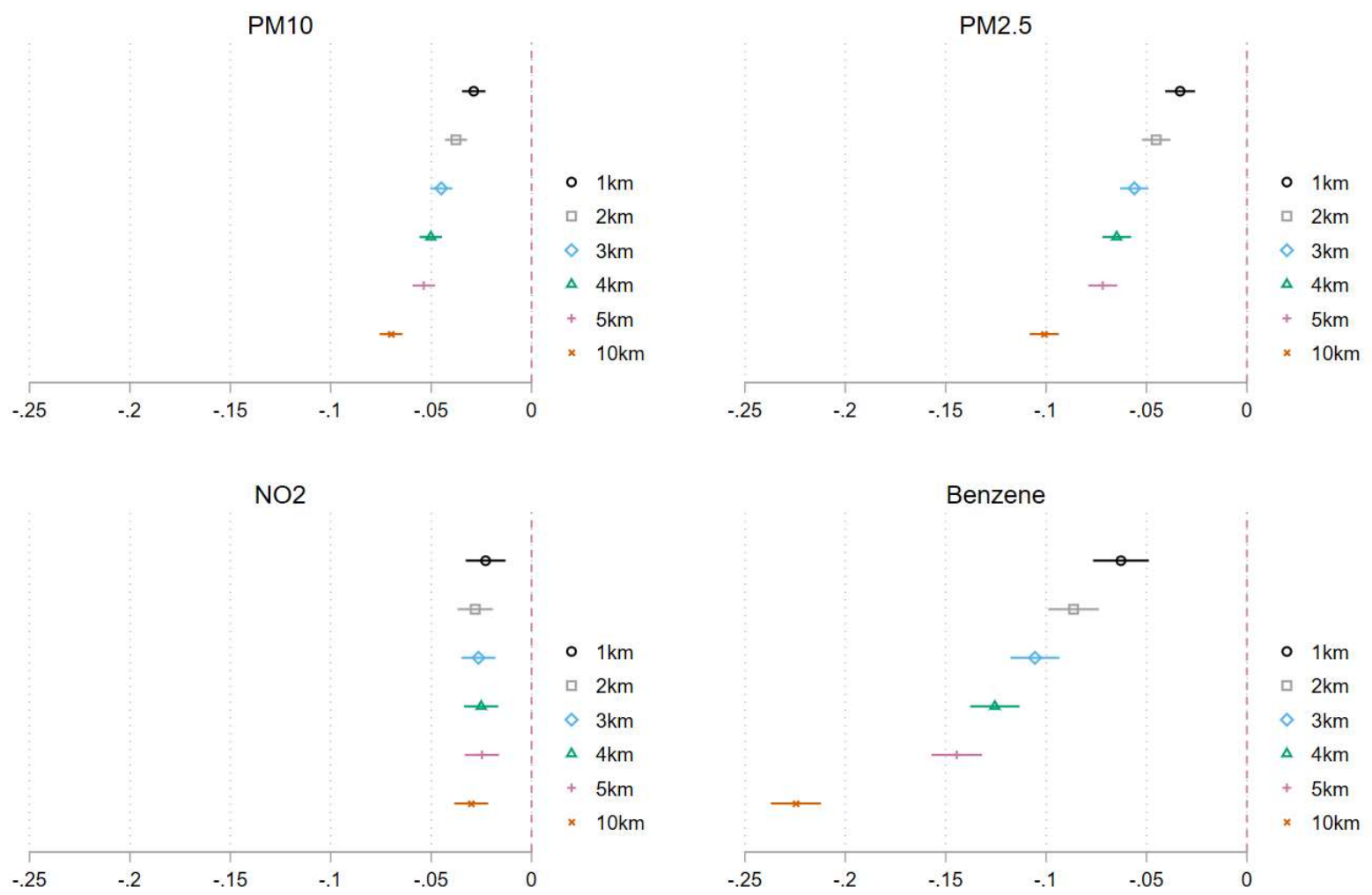

Note: Figure 3 displays the DiD estimates of equation (1) on air pollutants PM10, PM2.5, NO2 and Benzene, using as control group schools at $1 \mathrm{~km}, 2 \mathrm{~km}, 3 \mathrm{~km}, 4 \mathrm{~km}, 5 \mathrm{~km}$ and $10 \mathrm{~km}$ from the CCZ.

However, did the policy also reduce school absence in targeted areas? In table 2, we focus on absences as our main dependent variable. By trend, the DiD estimates on absences indicate a reduction in absences due to the policy when compared to schools within $3-10 \mathrm{~km}$ distance to the CCZ. However, the estimates are small in magnitude and not significantly different from zero. These overall estimates thus lead us to the conclusion that the CCZ policy did not affect school absences in a meaningful way. However, as we have argued earlier, the policy might have benefited more some groups, and different socio-economic groups in turn might react differently to improvements in air pollution. 
Table 2. DID Estimator for absences

\begin{tabular}{lcccccc}
\hline & $(1)$ & $(2)$ & $(3)$ & $(4)$ & $(5)$ & $(6)$ \\
Absences & $1 \mathrm{~km}$ & $2 \mathrm{~km}$ & $3 \mathrm{~km}$ & $4 \mathrm{~km}$ & $5 \mathrm{~km}$ & $10 \mathrm{~km}$ \\
\hline & & & & & & \\
DiD & 0.055 & 0.006 & -0.051 & -0.004 & -0.025 & -0.035 \\
& $(0.228)$ & $(0.243)$ & $(0.237)$ & $(0.237)$ & $(0.236)$ & $(0.242)$ \\
\hline Observations & 133 & 231 & 346 & 477 & 598 & 1,234 \\
R-squared & 0.736 & 0.737 & 0.743 & 0.762 & 0.758 & 0.782 \\
School FE & YES & YES & YES & YES & YES & YES \\
Year FE & YES & YES & YES & YES & YES & YES \\
\hline
\end{tabular}

Note: The point estimate is the DID estimator of equation (1). Standard errors are clustered at the school and LSOA level. All the models include year and school fixed effects. Other control variables are dummies for the quantiles for: \% of students with English as first language, \% of native British students, \% of boys, and the IMD rank of the school neighbourhood. Moreover, we introduce weights for the number of pupils in the school. P-values: $* * * \mathrm{p}<0.001, * *$ $\mathrm{p}<0.01, * \mathrm{p}<0.05$

\section{SES differences, air pollution and absences}

We first inquire how SES stratifies the improvements in air quality in Table 3 by adding an interaction term between the $\mathrm{DiD}$ estimator and the $\%$ of students known to be eligible to free meal in school ${ }^{12}$. It is important to note that we use the average percentage of students eligible to free school meal over the whole period of analysis to have a more stable indicator of school SES that is less susceptible to yearly variations. The interaction does not show any substantive results except for NO2 which shows a counteracting interaction, thereby suggesting a lower reduction in air pollution at low SES schools ${ }^{13}$.

Table 3. Air Pollution and the stratified effect by school SES

\begin{tabular}{lcccc}
\hline & $(1)$ & $(2)$ & $(3)$ & $(4)$ \\
VARIABLES & PM10 & PM2.5 & NO2 & Benzene \\
\hline \multirow{2}{*}{ DiD } & & & & \\
& $-0.077^{* * *}$ & $-0.103 * * *$ & $-0.053^{* * *}$ & $-0.241^{* * *}$ \\
DiD*FSM & $(0.007)$ & $(0.010)$ & $(0.011)$ & $(0.012)$ \\
& 0.000 & 0.000 & $0.001^{*}$ & 0.001 \\
& $(0.000)$ & $(0.000)$ & $(0.000)$ & $(0.000)$ \\
\hline Observations & 1,234 & 1,234 & 1,234 & 1,234 \\
R-squared & 0.973 & 0.961 & 0.975 & 0.885 \\
School FE & YES & YES & YES & YES \\
Year FE & YES & YES & YES & YES \\
\hline
\end{tabular}

Note: The point estimate is the DID estimator of equation (1). Standard errors are clustered at the school and LSOA level. All the models include year and school fixed effects. Other control variables are dummies for the quantiles for: \% of students with English as first language, \% of native British students, \% of boys, and the IMD rank of the school neighbourhood. P-values: *** $\mathrm{p}<0.001, * * \mathrm{p}<0.01, * \mathrm{p}<0.05$

\footnotetext{
${ }^{12}$ In this analysis we use schools at $10 \mathrm{~km}$ as our control group.

${ }^{13}$ In the Appendix, in Figure A1 we report the AME for NO2 showing a smaller decrease at higher levels of students eligible to free school meal.
} 
In Table 4, we furthermore repeat the analysis with absences as the dependent variable but introduce an interaction with free school meals eligibility. We observe that the interaction shows a negative value of -0.045 with $1 \mathrm{~km}$ boundaries, suggesting that an increase in the average percentage of students eligible to Free Meal is associated with a larger decrease in absences in the treated group. However, the DiD estimator exposes a positive sign indicating that the baseline group represented by schools with $0 \%$ of students eligible to free meal experience an increase of 1.24 percentage points in absences. In contrast, if $40 \%$ of the students are eligible to free school meal, we estimate a decrease of 0.56 percentage points in absences due to the policy ${ }^{14}$. Moreover, the coefficient of the main effect and the interaction remains very stable in its effect size across varying distances from the CCZ. Results thus are very robust compared across different control groups.

Overall, the results suggest a decrease in particulate matter and benzene within the CCZ for all students. Only for reduction in NO2 have mainly profited high SES pupils. However, we observe a stratified effect of the congestion charge policy on school absences: tightening the restriction in inner London has mostly benefitting low SES students.

Table 4. Absences, DID and the stratified effect by school SES

\begin{tabular}{lcccccc}
\hline & $(1)$ & $(2)$ & $(3)$ & $(4)$ & $(5)$ & $(6)$ \\
& $1 \mathrm{~km}$ & $2 \mathrm{~km}$ & $3 \mathrm{~km}$ & $4 \mathrm{~km}$ & $5 \mathrm{~km}$ & $10 \mathrm{~km}$ \\
\hline \multirow{2}{*}{ DID } & & & & & & \\
& $1.239^{*}$ & $1.304^{*}$ & $1.192^{*}$ & $1.218^{*}$ & $1.204^{*}$ & $1.209^{*}$ \\
DiD*FSM & $(0.484)$ & $(0.515)$ & $(0.506)$ & $(0.502)$ & $(0.503)$ & $(0.504)$ \\
& $-0.045^{*}$ & $-0.047^{*}$ & $-0.046^{*}$ & $-0.044^{*}$ & $-0.044^{*}$ & $-0.044^{*}$ \\
& $(0.020)$ & $(0.022)$ & $(0.022)$ & $(0.022)$ & $(0.022)$ & $(0.022)$ \\
\hline Observations & 133 & 231 & 346 & 477 & 598 & 1,234 \\
R-squared & 0.753 & 0.744 & 0.748 & 0.767 & 0.762 & 0.784 \\
Controls & YES & YES & YES & YES & YES & YES \\
School FE & YES & YES & YES & YES & YES & YES \\
Year FE & YES & YES & YES & YES & YES & YES \\
\hline
\end{tabular}

Note: The point estimate is the DID estimator of equation (1). Standard errors are clustered at the school and LSOA level. All the models include year and school fixed effects. Other control variables are dummies for the quantiles for: \% of students with English as first language, \% of native British students, \% of boys, and the IMD rank of the school neighbourhood. Moreover, we introduce weights for the number of pupils in the school. P-values: $* * * p<0.001, * *$ $\mathrm{p}<0.01, * \mathrm{p}<0.05$

\footnotetext{
${ }^{14}$ In the Appendix, in Figure A2 we report the AME for absences showing a decrease in absences at higher levels of students eligible to free school meal. However, we observe statistically significant results only at high levels of eligibility to free school meal.
} 


\section{Further analysis: spill-over effects, gender differences, age and test scores.}

\section{Spill-over effects}

Policies targeting air pollution may determine positive and negative spill-over effects (Fang et al., 2019; Feng et al., 2020). In the case of the CCZ in London, we can expect benefits for neighbouring areas as lower traffic and air pollution in the central area might also benefit the adjacent areas. We could already observe some hints of a positive spillover effect in Figure 1, where areas adjacent to the $\mathrm{CCZ}$ show a larger reduction in air pollution compared to more distant areas. We tested the existence of a spillover effect running a DiD analysis using the schools settled within $1 \mathrm{~km}$, $2 \mathrm{~km}$ and $3 \mathrm{~km}$ from the CCZ as the treated group and the schools within $10 \mathrm{~km}$ from the CCZ as the control group. We used different specifications of our "treated" group to test if there is a decrease of the spillover effect when we enlarge our sample to schools more distant from the CCZ.

First, we explore the results for air pollution (Appendix: Figure A3): we observe a reduction in all pollutants but NO2 at $1 \mathrm{~km}, 2 \mathrm{~km}$ and $3 \mathrm{~km}$ from the CCZ. The reduction is larger for the areas at $1 \mathrm{~km}$ from the $\mathrm{CCZ}$ and for Benzene. As expected, the decrease is smaller compared to the estimates we found for the $\mathrm{CCZ}$ area as seen in Figure 3. However, the reductions are still significantly larger than in among more distant schools. In addition, we observe a smaller decrease at lower SES schools for PM2.5 and Benzene at 1km (Appendix: Table A2) and 2km (Appendix: Table A3) but not at 3km (Appendix: Table A4).

By trend, the spillover effect on all school absences shows a reduction at $1 \mathrm{~km}, 2 \mathrm{~km}$ but an increase at $3 \mathrm{~km}$. However, results are not statistically significant (Appendix: Table A5). In additional analyses, we again included the interaction with free school meal. As in our main analysis, we observe an increase in absences at schools with low percentages of students eligible to free school meal and an decrease at higher free school meal rates (Appendix: Table A6). However, results are statistically significant only at $1 \mathrm{~km}$ from the $\mathrm{CCZ}$, suggesting the effect to fade away at higher distances from the CCZ. Overall, results for absences at $1 \mathrm{~km}$ mirror those found in the main analysis in Table 4.

\section{Gender differences}

Previous studies on the effect of air pollution have found boys to be more vulnerable than girls. For example, boys have a larger incidence of asthma and lower test scores when exposed to high levels of pollution compared to girls (Azamandeh et al., 2021). We inquire the differing susceptibility of boys to air pollution introducing an interaction between the DiD estimator and the $\%$ of boys in the school. The negative interaction term between the proportion of boys in the school 
and the $\mathrm{DiD}$ estimator suggest that the policy leads to a larger decrease in absences in schools with more boys (Appendix: Table A7). Nonetheless, we find a positive coefficient for the baseline group suggesting an increase in absences in schools with a very low percentage of boys. Consequently, our results confirm previous findings on the higher risks of air pollution for boys.

Age

Age is a factor that might affect susceptibility to environmental stressors. For example, in studies on temperature and cognitive abilities younger children are more likely to perform worse at school at higher temperatures (Park, Behrer \& Goodman, 2021). Our full sample of schools comprises state funded primary schools (age 5-11), state funded secondary schools (age 11-18) and special schools (11-18) ${ }^{15}$. We performed the DiD analysis with absences as our outcome using the Equation (1) separately by primary and secondary schools to observe if the age difference in the attendance of these schools affects our results ${ }^{16}$. The results without separating by free school meal do not show any substantial results. However, adding the interaction shows a decrease in absences with a higher $\%$ of students eligible to free school only in State funded secondary schools (Appendix: Table A8), i.e. among older low SES students.

\section{Test scores}

Air pollution affects school attendance that is a factor influencing test scores (Goodman, 2014). Consequently, we hypothesise that the decline of air pollution in the CCZ area could have increased students test scores. We test this hypothesis running a DiD as in Equation (1), using the standardized total average scores of the schools ${ }^{17}$. The standardized test score is only available from 2011 to 2019 and on a reduced sample of schools (approximately $25 \%$ of missing values). The results on the test scores show a reduction in the test scores but these estimates do not reach statistical significance (Appendix: Table A9). We also looked at the stratified effect on test scores adding an interaction with free school meal (Appendix: Table A10). Though, by trend, we again observe only beneficial effects among low SES schools, the interaction that is not statistically significant. However,

\footnotetext{
${ }^{15}$ A description of these schools is provided here: https:/www.gov.uk/government/statistics/schools-pupils-and-theircharacteristics-january-2019.

${ }^{16}$ We do not perform the analysis on special schools as the sample is too small for this purpose

${ }^{17}$ The data is freely available on the website provided by the British Ministry of Education https://www.compareschool-performance.service.gov.uk/download-data. An accurate description of the data is provided here: https://www.gov.uk/government/publications/understanding-school-and-college-performance-measures/understandingschool-and-college-performance-measures. Moreover, it should be noted that year-on-year comparability is limited when using this data as the calculation of the average score has changed over time. However, we use a standardized score to limit bias.
} 
the results are suggestive of a similar stratified effect of the $\mathrm{DiD}$ estimator on test scores as for absences.

\section{Robustness checks}

We run further tests to check the robustness of our results. First, we tested three alternative SES measures. We used a time varying continuous variable for SES, the IMD rank of the school's neighbourhood and a categorical variable that classifies a school with more than $35 \%$ of students eligible for free school meal as "Low SES", 20 to 35\% as "Medium SES" and, lower than 20\% as "High SES"18. All three measures replicate the main findings (Appendix: Table A11).

The parallel trends assumption is crucial for consistency of the Difference in Difference estimator. In Figure A4 of the Appendix, we depict the time trends in absences stratified by the three SES categories used in the analysis. Figure A4 clearly shows a reduction in absences in the CCZ area from 2016 and for low SES schools, and a slight increase among high SES schools in the CCZ. However, we do not observe diverging trends before 2016.

An additional challenge of a DiD approach with repeated cross-sectional data is determined by compositional changes in the unit of analysis. In our case, the student composition of schools might vary year-to-year or during the time of the treatment biasing our results. We tested for compositional changes running Equation (1) on the following outcomes: \% of students eligible to free school meal, \% of students with English as first language and \% of native British students. Results suggest no compositional changes in $\%$ of students eligible to free school meal and the $\%$ of native British students (Appendix: Table A12). Conversely, there is an increase in the \% of students with English as first language ${ }^{19}$. This finding is likely driven by an increase in birth rates within the cohorts between 2002 and 2013, which was higher among non-UK born women. Combined with a high immigrant share in central London, this has caused a disproportionate increase in children from nonUK born parents across schools within the CCZ area.

We further inquired which kind of absences have been reduced through the policy. More precisely, we replicate results in Table 4 separating absences by the following classification: authorized, unauthorized, illness related, and late arrivals. We report the results using the $10 \mathrm{~km}$ boundary (Appendix: Table A13). The results for authorized absences mirror those found in table 3 showing an increase in the baseline group and a reduction within schools with a high \% of students eligible to free school meal. For the other types of absences, the findings are not significant, except

\footnotetext{
${ }^{18}$ This categorization is based on the one used by the Ministry of Education.

${ }^{19}$ The interaction with free school meal does not show any substantial results. Results are available if requested to the authors.
} 
for illness that shows a positive sign for school with a very low percentage of free school meal eligibility.

An alternative factor which might explain our results is commuting time, as decreased traffic could reduce the time spent to reach the school and diminish the perceived cost of attending school for low SES children. To rule out this potential hypothesis we collected data on the median distance of the pupils from school by SES of the school from 2011 to $2016^{20}$. The median distance of pupils attending a High SES school is of $0.92 \mathrm{~km}$, in Medium SES schools of $0.71 \mathrm{~km}$ and in Low SES schools of $0.68 \mathrm{~km}$. The low median distance from schools leads us to rule out the possibility that changes in commuting time are driving our results for low SES students.

\section{Discussion \& Conclusions}

Air pollution is a major threat to pupils' school performance and cardio-respiratory health. Here, we analysed the effectiveness of tightening traffic regulations in improving air quality at schools and the benefits for pupils captured by school absences in London. The results revealed four main findings. First, the stricter policies have been effective in reducing schools' exposure to toxic pollutants, mostly to particulate matter. Secondly, in the pooled sample of schools, there is no substantive decline in school absences. Thirdly, we found that the policy decreased school absences for low SES schools, i.e.: the schools with the highest percentage of pupils eligible to free meal. However, absences increased in high SES schools. Fourthly, we identified positive spillover effects for schools just outside the CCZ. Consequently, environmental policies show to be effective in tackling air pollution, have positive spillover effects and benefit mostly the poor. These findings corroborate previous findings acknowledging the existence of disparities in vulnerability to air pollution between high and low SES individuals (Liu et al., 2021; Forastiere et al., 2007).

Presumably, low-SES children already suffer from respiratory conditions (e.g.: asthma, allergies, rhinitis), which could be aggravated by higher levels of air pollution (Wood et al., 2015). Moreover, low-SES parents might have lower means to shield their children from perilous outdoor conditions and keep them at home during days of high air pollution. Conversely, the increase in absences in high SES schools could be determined by behavioural responses. Parents of high SES children are more likely to enact compensatory behaviours to protect their children from suffering the exposure to air pollution (Bernardi, 2014; Diekmann et al. 2020; Torche, 2018). Likely, in the CCZ after 2016 when the new mayor Sadiq Khan took office and started to stress the risks of air quality in central London high SES parents might have started to take actions to protect their children keeping

\footnotetext{
${ }^{20}$ Data on distance from school and other metrics is present in the UK Datastore: https://data.london.gov.uk/dataset/london-schools-atlas
} 
them at home during polluted days. For example, previous studies have shown individuals buying extra medical insurance or taking precautionary behaviours when exposed to high levels of pollution (Chen \& Chen, 2020; Yoo, 2021). However, precautionary behaviours showed to not coincide with hospitalization for respiratory diseases possibly explaining the decrease in air pollution for low SES students that are more likely to suffer from respiratory disease and to not undertake compensatory behaviours (Janke, 2014).

Our work is not free from caveats. The main drawback of our analysis is that we cannot test mechanisms. Moreover, we use school level instead of individual level information determining strong limitations on our ability to robustly capture heterogeneous effects among individuals of different groups within the same school and constraining our analysis on repeated cross-sectional data on the schools. Individual level data could allow the use of student fixed effects controlling critical confounding factors that we are not able to rule out. Moreover, we do not have information on the exact address of residence of the children and we cannot infer if the exposure to air pollution driving our results mostly happens at home, on the way to school or at the school premises.

We conclude suggesting three possible venues of further research. First, inquiring the specific mechanisms that determine an SES gradient in the effect of environmental policies could permit to target the most vulnerable. Secondly, the use of repeated observations at the individual level could allow to observe short-term and long-term improvements in children health. Finally, our study is focused on London, a wealthy city in a developed country, which might downwardly bias our estimates raising important questions on the role those environmental policies could play in countries with lower air quality and economic development.

\section{References}

Alotaibi, R., Bechle, M., Marshall, J. D., Ramani, T., Zietsman, J., Nieuwenhuijsen, M. J., \& Khreis, H. (2019). Traffic related air pollution and the burden of childhood asthma in the contiguous United States in 2000 and 2010. Environment International, 127, 858-867. https://doi.org/10.1016/j.envint.2019.03.041

Amanzadeh, N., Vesal, M., \& Ardestani, S. F. F. (2020). The impact of short-term exposure to ambient air pollution on test scores in Iran. Population and Environment, 41(3), 253-285. https://doi.org/10.1007/s11111-019-00335-4

Barnes, J. H., Chatterton, T. J., \& Longhurst, J. W. S. (2019). Emissions vs exposure: Increasing injustice from road traffic-related air pollution in the United Kingdom. Transportation 
Research Part D: Transport and Environment, 73, 56-66.

\section{https://doi.org/10.1016/j.trd.2019.05.012}

Bernardi, Fabrizio. (2014). Compensatory Advantage as a Mechanism of Educational Inequality: A Regression Discontinuity Based on Month of Birth». Sociology of Education 87, n. 2: 7488. https://doi.org/10.1177/0038040714524258.

Buka, I. Koranteng S., Osornio-Vargas A. (2006). The effects of air pollution on the health of children. Paediatrics \& Child Health 11, n. 8 : 513-16.

Cameron, A. Colin, e Douglas L. Miller. (2015) A Practitioner's Guide to Cluster-Robust Inference. Journal of Human Resources 50, n. 2: 317-72. https://doi.org/10.3368/jhr.50.2.317.

Cameron, A. Colin, Jonah B. Gelbach, e Douglas L. Miller. (2011) Robust Inference With Multiway Clustering». Journal of Business \& Economic Statistics 29, n. 2: 238-49.

Chen, Fanglin, e Zhongfei Chen. (2020)Air Pollution and Avoidance Behavior: A Perspective from the Demand for Medical Insurance». Journal of Cleaner Production 259: 120970. https://doi.org/10.1016/j.jclepro.2020.120970.

Colmer, Jonathan; Voorheis, John (2020): The grandkids aren't alright: the intergenerational effects of prenatal pollution exposure. In CEP Discussion Papers (dp1733). Available online at https://ideas.repec.org/p/cep/cepdps/dp1733.html.

Colmer, J., Hardman, I., Shimshack, J., \& Voorheis, J. (2020). Disparities in PM2.5 air pollution in the United States. Science, 369(6503), 575-578. https://doi.org/10.1126/science.aaz9353

Cope, S. F., Ungar, W. J., \& Glazier, R. H. (2008). Socioeconomic Factors and Asthma Control in Children. Pediatric Pulmonology, 43(8), 745-752. https://doi.org/10.1002/ppul.20847

Currie, J., Hanushek, E. A., Kahn, E. M., Neidell, M., \& Rivkin, S. G. (2009). Does Pollution Increase School Absences? The Review Of Economics And Statistics, 13.

Diekmann, A., Bruderer Enzler, H., Hartmann, J., Kurz, K., Liebe, U., \& Preisendörfer, P. (2020). Environmental Inequality in Four European Cities: A Study Combining Household Survey and Geo-Referenced Data. Unpublished Working Paper. 
Ebenstein, A., Lavy, V., \& Roth, S. (2016). The Long-Run Economic Consequences of High-Stakes Examinations: Evidence from Transitory Variation in Pollution. American Economic Journal: Applied Economics, 8(4), 36-65. https://doi.org/10.1257/app.20150213

Fang, Delin, Bin Chen, Klaus Hubacek, Ruijing Ni, Lulu Chen, Kuishuang Feng, e Jintai Lin. (2019). Clean Air for Some: Unintended Spillover Effects of Regional Air Pollution Policies. Science Advances 5, n. 4 : eaav4707. https://doi.org/10.1126/sciadv.aav4707. Feng, Tong, Huibin Du, Zhongguo Lin, e Jian Zuo. (2020) Spatial Spillover Effects of Environmental Regulations on Air Pollution: Evidence from Urban Agglomerations in China». Journal of Environmental Management 272: 110998. https://doi.org/10.1016/j.jenvman.2020.110998.

Forastiere, F., Stafoggia, M., Tasco, C., Picciotto, S., Agabiti, N., Cesaroni, G., \& Perucci, C. A. (2007). Socioeconomic status, particulate air pollution, and daily mortality: Differential exposure or differential susceptibility. American Journal of Industrial Medicine, 50(3), 208216. https://doi.org/10.1002/ajim.20368

Goodman, Joshua. (2014) Flaking Out: Student Absences and Snow Days as Disruptions of Instructional Time». Working Paper. Working Paper Series. National Bureau of Economic Research.https://doi.org/10.3386/w20221.

Gong, T., Lundholm, C., Rejnö, G., Mood, C., Långström, N., \& Almqvist, C. (2014). Parental Socioeconomic Status, Childhood Asthma and Medication Use - A Population-Based Study. PLoS ONE, 9(9). https://doi.org/10.1371/journal.pone.0106579

Green, C. P., Heywood, J. S., \& Navarro Paniagua, M. (2020). Did the London congestion charge reduce pollution? Regional Science and Urban Economics, 84, 103573. https://doi.org/10.1016/j.regsciurbeco.2020.103573

Grineski, S. E., \& Collins, T. W. (2018). Geographic and social disparities in exposure to air neurotoxicants at U.S. public schools. Environmental Research, 161, 580-587. 
https://doi.org/10.1016/j.envres.2017.11.047

Grineski, S. E., Collins, T. W., \& Adkins, D. E. (2020). Hazardous air pollutants are associated with worse performance in reading, math, and science among US primary schoolchildren. Environmental Research, 181, 108925. https://doi.org/10.1016/j.envres.2019.108925

Guo, Y., Fengfeng Liu, Yuanan Lu, Zongfu Mao, Hanson Lu, Yanyan Wu, Yuanyuan Chu, et al. (2016). "Factors Affecting Parent's Perception on Air Quality_From the Individual to the Community Level”. International Journal of Environmental Research and Public Health 13, n. 5: 493. https://doi.org/10.3390/ijerph13050493.

Janke, K. (2014). Air Pollution, Avoidance Behaviour and Children's Respiratory Health: Evidence from England". Journal of Health Economics 38: 23-42. https://doi.org/10.1016/j.jhealeco.2014.07.002.

Jiang, X.-Q., Mei, X.-D., \& Feng, D. (2016). Air pollution and chronic airway diseases: What should people know and do? Journal of Thoracic Disease, 8(1), E31-E40. https://doi.org/10.3978/j.issn.2072-1439.2015.11.50

Kravitz-Wirtz, Nicole, Samantha Teixeira, Anjum Hajat, Bongki Woo, Kyle Crowder, e David Takeuchi. (2018) Early-Life Air Pollution Exposure, Neighborhood Poverty, and Childhood Asthma in the United States, 1990-2014. International Journal of Environmental Research and Public Health 15, n. 6: 1114. https://doi.org/10.3390/ijerph15061114.

Li, H., \& Ding, H. (2020). Causal Effects of the Abolition of London Western Charging Zone on Vehicle Emissions: A Regression Discontinuity Study. 2681-2692.

\section{https://doi.org/10.1061/9780784483053.226}

Liu, X., Behrman, J., Hannum, E., Wang, F., \& Zhao, Q. (2021). Same Environment, Stratified Impacts? Air Pollution, Extreme Temperatures, and Birth Weight in Southeast China (SSRN Scholarly Paper ID 3759319). Social Science Research Network.

https://papers.ssrn.com/abstract $=3759319$

Manduca, R., Sampson R.,(2021) Childhood Exposure to Polluted Neighborhood Environments and 
Intergenerational Income Mobility, Teenage Birth, and Incarceration in the USA».

Population and Environment. https://doi.org/10.1007/s11111-020-00371-5.

Manduca, R., Sampson R.,(2019) Punishing and Toxic Neighborhood Environments Independently Predict the Intergenerational Social Mobility of Black and White Children. Proceedings of the National Academy of Sciences 116, n. 16 7772-77. https://doi.org/10.1073/pnas.1820464116.

Mudway, I. S., Dundas, I., Wood, H. E., Marlin, N., Jamaludin, J. B., Bremner, S. A., Cross, L., Grieve, A., Nanzer, A., Barratt, B. M., Beevers, S., Dajnak, D., Fuller, G. W., Font, A., Colligan, G., Sheikh, A., Walton, R., Grigg, J., Kelly, F. J., ... Griffiths, C. J. (2019). Impact of London's low emission zone on air quality and children's respiratory health: A sequential annual cross-sectional study. The Lancet Public Health, 4(1), e28-e40.

\section{https://doi.org/10.1016/S2468-2667(18)30202-0}

Park, R. Jisung, A. Patrick Behrer, e Joshua Goodman. (2021) Learning Is Inhibited by Heat Exposure, Both Internationally and within the United States». Nature Human Behaviour 5, n. 1 : 19-27. https://doi.org/10.1038/s41562-020-00959-9.

Rüttenauer, T. (2018). Neighbours Matter: A Nation-wide Small-area Assessment of Environmental Inequality in Germany. Social Science Research, 70, 198-211. https://doi.org/10.1016/j.ssresearch.2017.11.009

Schwarzman, M., Schildroth, S., Bhetraratana, M., Alvarado, Á., \& Balmes, J. (2021). Raising standards to lower diesel emissions. Science, 371(6536), 1314-1316. https://doi.org/10.1126/science.abf8159

Stingone, J. A., \& Claudio, L. (2006). Disparities in the use of urgent health care services among asthmatic children. Annals of Allergy, Asthma \& Immunology, 97(2), 244-250. https://doi.org/10.1016/S1081-1206(10)60021-X

Tang, C. K. (2021). The Cost of Traffic: Evidence from the London Congestion Charge. Journal of Urban Economics, 121, 103302. https://doi.org/10.1016/j.jue.2020.103302 
Torche, Florencia. (2018) Prenatal Exposure to an Acute Stressor and Children's Cognitive Outcomes. Demography 55, n. 5 : 1611-39. https://doi.org/10.1007/s13524-018-0700-9.

Yoo, Geunsik. (2021) Real-Time Information on Air Pollution and Avoidance Behavior: Evidence from South Korea. Population and Environment 42, n. 3: 406-24. https://doi.org/10.1007/s11111-020-00368-0.

Wood, H. E., Marlin, N., Mudway, I. S., Bremner, S. A., Cross, L., Dundas, I., Grieve, A., Grigg, J., Jamaludin, J. B., Kelly, F. J., Lee, T., Sheikh, A., Walton, R., \& Griffiths, C. J. (2015). Effects of Air Pollution and the Introduction of the London Low Emission Zone on the Prevalence of Respiratory and Allergic Symptoms in Schoolchildren in East London: A Sequential Cross-Sectional Study. PLOS ONE, 10(8), e0109121. 


\section{Appendix}

Table A1 Policies regulating traffic in London

\begin{tabular}{|l|l|l|}
\hline Policy & $\begin{array}{l}\text { Year of } \\
\text { adoption }\end{array}$ & Fee \\
\hline $\begin{array}{l}\text { Congestion } \\
\text { Charge }\end{array}$ & 2003 & $5 £$ \\
\hline $\begin{array}{l}\text { Euro } 4 \\
\text { mandatory for all } \\
\text { cars }\end{array}$ & 2005 & $8 £$ \\
\hline $\begin{array}{l}\text { Extension of the } \\
\text { CC to the West } \\
\text { Zone }\end{array}$ & 2007 & No fee change \\
\hline $\begin{array}{l}\text { London Low } \\
\text { Emission Zone }\end{array}$ & 2008 & polluting \\
\hline $\begin{array}{l}\text { Retraction of the } \\
\text { extension to the } \\
\text { west ares }\end{array}$ & 2011 & $12.50 £$ \\
\hline $\begin{array}{l}\text { Change in } \\
\text { discount scheme, } \\
\text { applicable only } \\
\text { to low emission } \\
\text { cars }\end{array}$ & 2013 & $10 £$ \\
\hline $\begin{array}{l}\text { Change in the } \\
\text { Fee }\end{array}$ & 2014 & fars \\
\hline $\begin{array}{l}\text { Euro } 6 \\
\text { chandatory for all }\end{array}$ & 2017 \\
\hline specific car \\
categories
\end{tabular}


Table A2 Air pollution, Spillover effect at $1 \mathrm{~km}$ and interaction with Free school meal

\begin{tabular}{lcccc}
\hline & $(1)$ & $(2)$ & $(3)$ & $(4)$ \\
& PM10 & PM25 & NO2 & Benzene \\
\hline Spillover 1km & & & & \\
& $-0.030^{* * *}$ & $-0.050^{* * *}$ & -0.032 & $-0.124^{* * *}$ \\
Spillover 1km *FSM & $(0.008)$ & $(0.010)$ & $(0.017)$ & $(0.022)$ \\
& -0.000 & $-0.001^{*}$ & 0.001 & $-0.001^{*}$ \\
\hline Observations & $(0.000)$ & $(0.000)$ & $(0.000)$ & $(0.001)$ \\
R-squared & 1,168 & 1,168 & 1,168 & 1,168 \\
School FE & 0.975 & 0.965 & 0.971 & 0.892 \\
Year FE & YES & YES & YES & YES \\
\hline
\end{tabular}

Note: The point estimate is the DID estimator of equation (1). Standard errors are clustered at the school and LSOA level. All the models include year and school fixed effects. Other control variables are dummies for the quantiles for: \% of students with English as first language, \% of native British students, \% of boys, and the IMD rank of the school neighbourhood. P-values: ${ }^{* * *} \mathrm{p}<0.001,{ }^{* *} \mathrm{p}<0.01,{ }^{*} \mathrm{p}<0.05$

Table A3 Air pollution, Spillover effect at $2 \mathrm{~km}$ and interaction with Free school meal

\begin{tabular}{lcccc}
\hline & $(1)$ & $(2)$ & $(3)$ & $(4)$ \\
& PM10 & PM25 & NO2 & Benzene \\
\hline \multirow{2}{*}{ Spillover 2km } & $-0.032 * * *$ & $-0.051 * * *$ & -0.012 & $-0.139 * * *$ \\
& $(0.004)$ & $(0.005)$ & $(0.008)$ & $(0.011)$ \\
Spillover 2km*FSM & -0.000 & $-0.000^{* *}$ & 0.000 & $-0.001^{*}$ \\
& $(0.000)$ & $(0.000)$ & $(0.000)$ & $(0.000)$ \\
\hline Observations & 1,168 & 1,168 & 1,168 & 1,168 \\
R-squared & 0.976 & 0.969 & 0.971 & 0.905 \\
School FE & YES & YES & YES & YES \\
Year FE & YES & YES & YES & YES \\
Note: The point estimate is the DID estimator of equation $(1)$. Standard errors are clustered at the school and LSOA \\
level. All the models include year and school fixed effects. Other control variables are dummies for the quantiles for: \% \\
of students with English as first language, $\%$ of native British students, \% of boys, and the IMD rank of the school \\
neighbourhood. P-values: *** $\mathrm{p}<0.001, * * \mathrm{p}<0.01, * \mathrm{p}<0.05$ & \multicolumn{4}{l}{}
\end{tabular}


Table A4 Air pollution, Spillover effect at $3 \mathrm{~km}$ and interaction with Free school meal

\begin{tabular}{lcccc}
\hline & $(1)$ & $(2)$ & $(3)$ & $(4)$ \\
& PM10 & PM25 & NO2 & Benzene \\
\hline Spillover 3km & $-0.032 * * *$ & $-0.053 * * *$ & -0.009 & $-0.144 * * *$ \\
& $(0.003)$ & $(0.004)$ & $(0.006)$ & $(0.009)$ \\
Spillover 3km*FSM & -0.000 & -0.000 & 0.000 & -0.000 \\
& $(0.000)$ & $(0.000)$ & $(0.000)$ & $(0.000)$ \\
\hline Observations & 1,168 & 1,168 & 1,168 & 1,168 \\
R-squared & 0.977 & 0.971 & 0.971 & 0.916 \\
School FE & YES & YES & YES & YES \\
Year FE & YES & YES & YES & YES \\
Note: The point estimate is the DID estimator of equation $(1)$. Standard errors are clustered at the school and LSOA \\
level. All the models include year and school fixed effects. Other control variables are dummies for the quantiles for: \% \\
of students with English as first language, \% of native British students, \% of boys, and the IMD rank of the school \\
neighbourhood. P-values: *** $\mathrm{p}<0.001, * * \mathrm{p}<0.01, *$ p $<0.05$ & \multicolumn{4}{l}{}
\end{tabular}

Table A5 Spillover effect and absences

\begin{tabular}{lccc}
\hline & $(1)$ & $(2)$ & $(3)$ \\
DiD & Absences & Absences & Absences \\
\hline Spillover 1km & -0.071 & & \\
& $(0.086)$ & & \\
Spillover 2km & & -0.088 & \\
& & $(0.065)$ & \\
Spillover 3km & & & 0.011 \\
& & & $(0.057)$ \\
\hline Observations & 1,168 & 1,168 & 1,168 \\
R-squared & 0.788 & 0.788 & 0.788 \\
School FE & YES & YES & YES \\
Year FE & YES & YES & YES \\
\hline
\end{tabular}

Note: The point estimate is the DID estimator of equation (1). Standard errors are clustered at the school and LSOA level. All the models include year and school fixed effects. Other control variables are dummies for the quantiles for: \% of students with English as first language, \% of native British students, \% of boys, and the IMD rank of the school neighbourhood. Moreover, we introduce weights for the number of pupils in the school. P-values: *** $p<0.001, * *$ $\mathrm{p}<0.01,{ }^{*} \mathrm{p}<0.05$ 
Table A6. Spillover effect, absences and interaction with Free School Meal

\begin{tabular}{lccc}
\hline & $(1)$ & $(2)$ & $(3)$ \\
DiD & Absences & Absences & Absences \\
\hline & & & \\
Spillover 1km & $0.811^{* *}$ & & \\
& $(0.313)$ & & \\
Spillover 1km * FSM & $-0.022^{* *}$ & & \\
& $(0.008)$ & & \\
& & & \\
DiD Spillover 2km & & 0.206 & \\
& & $(0.253)$ & \\
DiD Spillover 2km* FSM & & -0.007 & \\
& & $(0.007)$ & \\
DiD Spillover 3km & & & 0.248 \\
& & & $-0.185)$ \\
DiD Spillover 3km * FSM & & & $(0.005)$ \\
& & & 1,168 \\
Observations & 1,168 & 1,168 & 0.787 \\
R-squared & 0.787 & 0.787 & YES \\
School FE & YES & YES & YES \\
Year FE & YES & YES & Y
\end{tabular}

Note: The point estimate is the DID estimator of equation (1). Standard errors are clustered at the school and LSOA level. All the models include year and school fixed effects. Other control variables are dummies for the quantiles for: \% of students with English as first language, \% of native British students, \% of boys, and the IMD rank of the school neighbourhood. Moreover, we introduce weights for the number of pupils in the school. P-values: $* * * p<0.001, * *$ $\mathrm{p}<0.01, * \mathrm{p}<0.05$

Table A7. DID and differential effect by proportion of boys

\begin{tabular}{lcccccc}
\hline & $(1)$ & $(2)$ & $(3)$ & $(4)$ & $(5)$ & $(6)$ \\
& $1 \mathrm{~km}$ & $2 \mathrm{~km}$ & $3 \mathrm{~km}$ & $4 \mathrm{~km}$ & $5 \mathrm{~km}$ & $10 \mathrm{~km}$ \\
\hline \multirow{2}{*}{ DID } & $0.669^{* *}$ & $0.633^{*}$ & $0.585^{*}$ & $0.640^{* *}$ & $0.614^{*}$ & $0.608^{*}$ \\
& $(0.245)$ & $(0.252)$ & $(0.235)$ & $(0.241)$ & $(0.247)$ & $(0.250)$ \\
DID*Boys & $-0.013^{*}$ & $-0.013^{*}$ & $-0.013^{* *}$ & $-0.013^{* *}$ & $-0.013^{* *}$ & $-0.014^{* *}$ \\
& $(0.005)$ & $(0.005)$ & $(0.005)$ & $(0.005)$ & $(0.005)$ & $(0.005)$ \\
\hline Observations & 133 & 231 & 346 & 477 & 598 & 1,234 \\
R-squared & 0.749 & 0.742 & 0.747 & 0.766 & 0.761 & 0.784 \\
Controls & YES & YES & YES & YES & YES & YES \\
School FE & YES & YES & YES & YES & YES & YES \\
Year FE & YES & YES & YES & YES & YES & YES \\
\hline
\end{tabular}

Note: The point estimate is the DID estimator of equation (1). Standard errors are clustered at the school and LSOA level. All the models include year and school fixed effects. Other control variables are dummies for the quantiles for: \% of students with English as first language, \% of native British students, \% of boys, and the IMD rank of the school neighbourhood. Moreover, we introduce weights for the number of pupils in the school. P-values: $* * * \mathrm{p}<0.001, * *$ $\mathrm{p}<0.01, * \mathrm{p}<0.05$ 
Table A8. DiD and differential effect by School Type

\begin{tabular}{lcccc}
\hline & $\begin{array}{c}(1) \\
\text { State-funded } \\
\text { primary }\end{array}$ & $\begin{array}{c}(2) \\
\text { State-funded } \\
\text { secondary }\end{array}$ & $\begin{array}{c}(3) \\
\text { State-funded } \\
\text { primary }\end{array}$ & $\begin{array}{c}(4) \\
\text { State-funded } \\
\text { secondary }\end{array}$ \\
\hline & Absences & Absences & Absences & Absences \\
\hline DiD & & & & \\
& 0.140 & -0.182 & 0.322 & $2.901^{* * *}$ \\
DiD*FSM & $(0.125)$ & $(0.461)$ & $(0.293)$ & $(0.471)$ \\
& & & -0.006 & $-0.116^{* * *}$ \\
Observations & 961 & & $(0.009)$ & $(0.017)$ \\
R-squared & 0.751 & 0.764 & 961 & 227 \\
School FE & YES & YES & 0.749 & 0.765 \\
Year FE & YES & YES & YES & YES \\
Controls & YES & YES & YES & YES \\
\hline
\end{tabular}

Note: The point estimate is the DID estimator of equation (1). Standard errors are clustered at the school and LSOA level. All the models include year and school fixed effects. Other control variables are dummies for the quantiles for: \% of students with English as first language, \% of native British students, \% of boys, and the IMD rank of the school neighbourhood. Moreover, we introduce weights for the number of pupils in the school. P-values: $* * * \mathrm{p}<0.001, * *$ $\mathrm{p}<0.01, * \mathrm{p}<0.05$

Table A9. DiD and school level test scores

\begin{tabular}{|c|c|c|c|c|c|c|}
\hline Test score & $\begin{array}{l}(1) \\
1 \mathrm{~km}\end{array}$ & $\begin{array}{c}(2) \\
2 \mathrm{~km}\end{array}$ & $\begin{array}{c}(3) \\
3 \mathrm{~km}\end{array}$ & $\begin{array}{c}(4) \\
4 \mathrm{~km}\end{array}$ & $\begin{array}{c}(5) \\
5 \mathrm{~km}\end{array}$ & $\begin{array}{c}(6) \\
10 \mathrm{~km}\end{array}$ \\
\hline DiD & $\begin{array}{l}-0.220 \\
(0.127)\end{array}$ & $\begin{array}{l}-0.226^{*} \\
(0.107)\end{array}$ & $\begin{array}{l}-0.170 \\
(0.101)\end{array}$ & $\begin{array}{l}-0.157 \\
(0.096)\end{array}$ & $\begin{array}{l}-0.159 \\
(0.096)\end{array}$ & $\begin{array}{l}-0.149 \\
(0.094)\end{array}$ \\
\hline Observations & 106 & 156 & 268 & 370 & 457 & 932 \\
\hline R-squared & 0.558 & 0.590 & 0.629 & 0.652 & 0.656 & 0.665 \\
\hline School FE & YES & YES & YES & YES & YES & YES \\
\hline Year FE & YES & YES & YES & YES & YES & YES \\
\hline Controls & YES & YES & YES & YES & YES & YES \\
\hline $\begin{array}{l}\text { Note: The point } \\
\text { level. All the mod } \\
\text { of students with } \mathrm{E} \\
\text { neighbourhood. } \\
\mathrm{p}<0.01,{ }^{*} \mathrm{p}<0.05\end{array}$ & $\begin{array}{l}\text { is the DID } \\
\text { ide year ar } \\
\text { s first lang } \\
\text {, we intro }\end{array}$ & $\begin{array}{l}\text { mator of ec } \\
\text { chool fixed } \\
\text { e, } \% \text { of nat } \\
\text { e weights fo }\end{array}$ & $\begin{array}{l}\text { ion (1). Sta } \\
\text { ects. Other } \\
\text { British stu } \\
\text { ee number }\end{array}$ & $\begin{array}{l}\mathrm{d} \text { errors are } \\
\text { rol variable } \\
\% \text { of boy } \\
\text { pils in the }\end{array}$ & $\begin{array}{l}\text { ed at the sc } \\
\text { Immies for } \\
\text { e IMD ran } \\
\text { P-values: * }\end{array}$ & $\begin{array}{l}\text { nd LSOA } \\
\text { antiles for: \% } \\
\text { e school } \\
.001, * *\end{array}$ \\
\hline
\end{tabular}


Table A10. DiD, Free school meal and school level test scores

\begin{tabular}{lcccccc}
\hline Test score & $(1)$ & $(2)$ & $(3)$ & $(4)$ & $(5)$ & $(6)$ \\
& $1 \mathrm{~km}$ & $2 \mathrm{~km}$ & $3 \mathrm{~km}$ & $4 \mathrm{~km}$ & $5 \mathrm{~km}$ & $10 \mathrm{~km}$ \\
\hline \multirow{2}{*}{ DiD } & & & & & & \\
& -0.482 & $-0.474^{*}$ & -0.439 & $-0.487^{*}$ & -0.453 & -0.414 \\
DiD* FSM & $(0.243)$ & $(0.237)$ & $(0.238)$ & $(0.231)$ & $(0.232)$ & $(0.229)$ \\
& 0.009 & 0.008 & 0.009 & 0.011 & 0.010 & 0.009 \\
Observations & $(0.007)$ & $(0.007)$ & $(0.007)$ & $(0.007)$ & $(0.007)$ & $(0.007)$ \\
R-squared & 106 & 156 & 268 & 370 & 457 & 932 \\
School FE & 0.559 & 0.591 & 0.629 & 0.652 & 0.656 & 0.665 \\
Year FE & YES & YES & YES & YES & YES & YES \\
Controls & YES & YES & YES & YES & YES & YES \\
\hline
\end{tabular}

Note: The point estimate is the DID estimator of equation (1). Standard errors are clustered at the school and LSOA level. All the models include year and school fixed effects. Other control variables are dummies for the quantiles for: \% of students with English as first language, \% of native British students, \% of boys, and the IMD rank of the school neighbourhood. Moreover, we introduce weights for the number of pupils in the school. P-values: *** $\mathrm{p}<0.001,{ }^{* *}$ $\mathrm{p}<0.01, * \mathrm{p}<0.05$

Table A11. Alternative specification of SES

\begin{tabular}{|c|c|c|c|}
\hline Absences & $\begin{array}{c}(1) \\
\text { Yearly SES }\end{array}$ & $\begin{array}{c}(2) \\
\text { IMD Rank }\end{array}$ & $\begin{array}{c}(3) \\
\text { Categorical SES }\end{array}$ \\
\hline DID & $\begin{array}{l}1.02163^{*} \\
(0.42395)\end{array}$ & $\begin{array}{l}-0.78656 \\
(0.50174)\end{array}$ & $\begin{array}{l}0.491^{*} \\
(0.206)\end{array}$ \\
\hline DID*Yearly SES & $\begin{array}{l}-0.04579 * \\
(0.02217)\end{array}$ & & \\
\hline DID* IMD rank & & $\begin{array}{l}0.00006^{*} \\
(0.00003)\end{array}$ & \\
\hline DID*Medium SES & & & $\begin{array}{l}-0.380 \\
(0.281)\end{array}$ \\
\hline DID*Low SES & & & $-1.437^{*}$ \\
\hline Observations & 1,234 & 1,234 & 1,234 \\
\hline R-squared & 0.78438 & 0.78393 & 0.784 \\
\hline School FE & YES & YES & YES \\
\hline Year FE & YES & YES & YES \\
\hline
\end{tabular}

Note: The point estimate is the DID estimator of equation (1). Standard errors are clustered at the school and LSOA level. All the models include year and school fixed effects. Other control variables are dummies for the quantiles for: \% of students with English as first language, \% of native British students, \% of boys, and the IMD rank of the school neighbourhood. Moreover, we introduce weights for the number of pupils in the school. P-values: *** $\mathrm{p}<0.001, * *$ $\mathrm{p}<0.01, * \mathrm{p}<0.05$ 
Table A12. Compositional changes in schools

\begin{tabular}{lccc}
\hline Variables & Free school Meal & Native British & English as first language \\
DID & 0.958 & -0.544 & $5.307^{* * *}$ \\
& $(1.302)$ & $(0.995)$ & $(1.169)$ \\
\hline Observations & 1,234 & 1,234 & 1,234 \\
R-squared & 0.762 & 0.679 & 0.610 \\
School FE & YES & YES & YES \\
Year FE & YES & YES & YES \\
Controls & YES & YES & YES \\
\hline
\end{tabular}

Note: The point estimate is the DID estimator of equation (1). Standard errors are clustered at the school and LSOA

level. All the models include year and school fixed effects. Other control variables are dummies for the quantiles for: \% of students with English as first language, \% of native British students, \% of boys, and the IMD rank of the school neighbourhood. Moreover, we introduce weights for the number of pupils in the school. P-values: *** $p<0.001, * *$ $\mathrm{p}<0.01, * \mathrm{p}<0.05$

Table A13. Alternative specification of absences

\begin{tabular}{lccccc}
\hline Variables & Authorised absences & Unauthorised absences & Illness & Late arrival & Travel \\
DID & $0.671^{* *}$ & 0.512 & $0.344^{*}$ & 0.067 & -0.000 \\
& $(0.226)$ & $(0.391)$ & $(0.163)$ & $(0.049)$ & $(0.003)$ \\
DID*FSM & $-0.017^{*}$ & -0.027 & -0.006 & -0.002 & 0.000 \\
& $(0.007)$ & $(0.018)$ & $(0.005)$ & $(0.001)$ & $(0.000)$ \\
\hline Observations & 1,234 & 1,234 & 1,234 & 1,234 & 1,234 \\
R-squared & 0.762 & 0.679 & 0.610 & 0.437 & 0.411 \\
School FE & YES & YES & YES & YES & YES \\
Year FE & YES & YES & YES & YES & YES \\
Controls & YES & YES & YES & YES & YES \\
\hline
\end{tabular}

Note: The point estimate is the DID estimator of equation (1). Standard errors are clustered at the school and LSOA

level. All the models include year and school fixed effects. Other control variables are dummies for the quantiles for: \% of students with English as first language, \% of native British students, \% of boys, and the IMD rank of the school neighbourhood. Moreover, we introduce weights for the number of pupils in the school. P-values: *** $\mathrm{p}<0.001,{ }^{* *}$ $\mathrm{p}<0.01, * \mathrm{p}<0.05$ 
Figures

Figure A1. AME of the DiD estimator on NO2 by \% of Free school meal

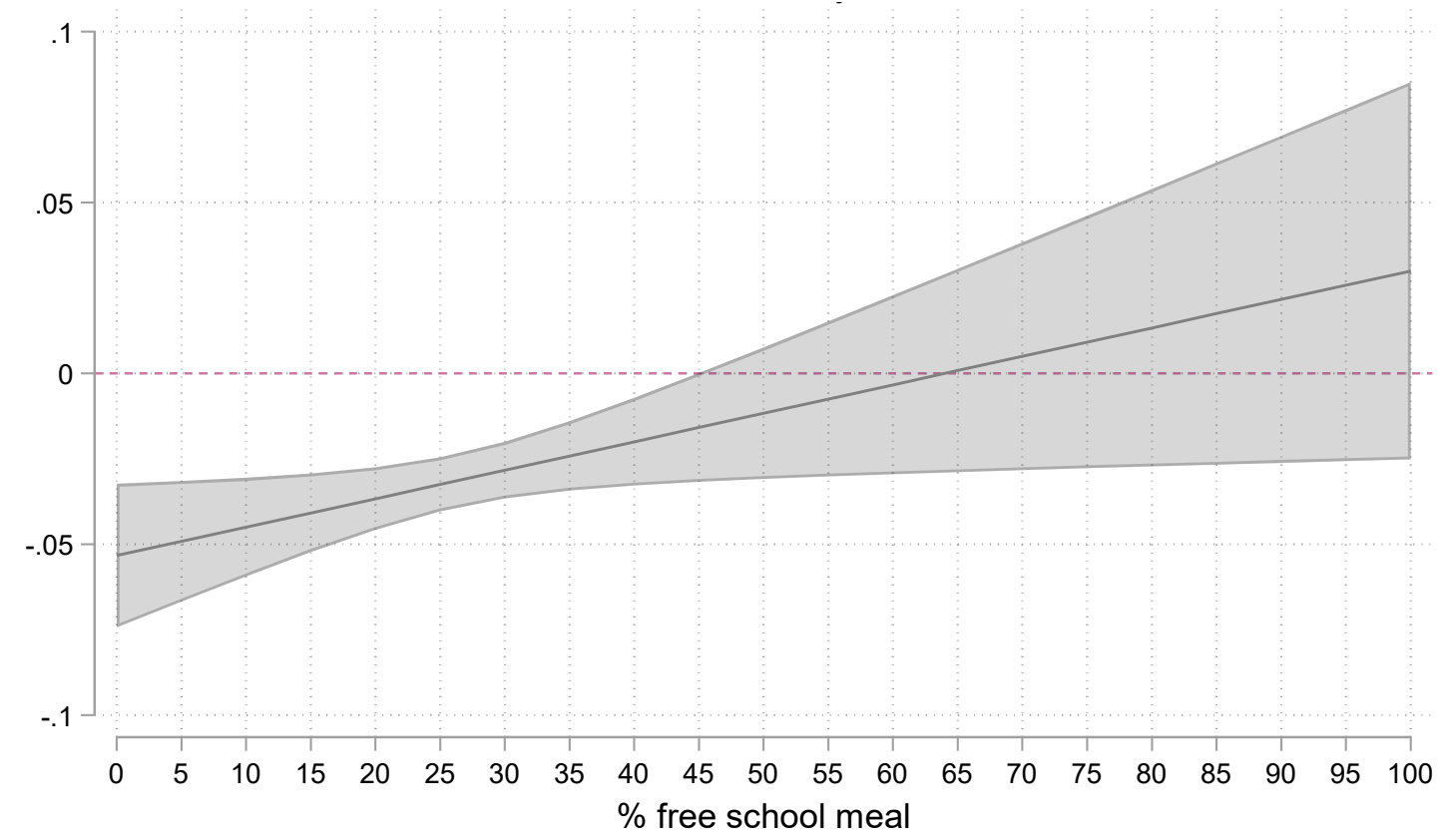

Note: the figure shows the average marginal effect (AME) of the DiD estimator on NO2 by \% of students eliglible to free school meal.

Figure A2. AME of DiD estimator on Absences by \% of Free school Meal

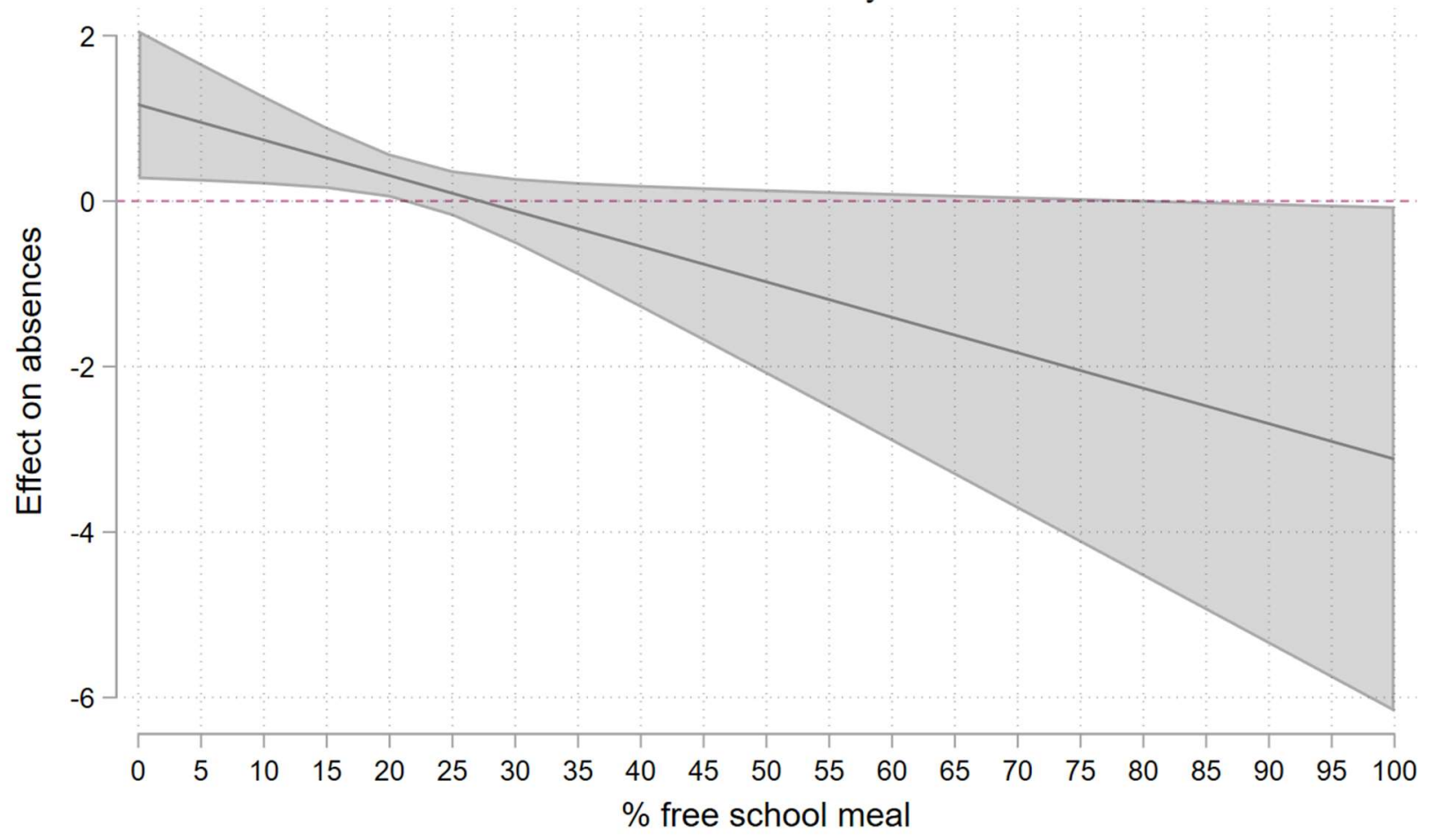

Note: the figure shows the average marginal effect (AME) of the DiD estimator on absences by $\%$ of students eliglible to free school meal. 
Figure A3. Spillover effects and air pollution
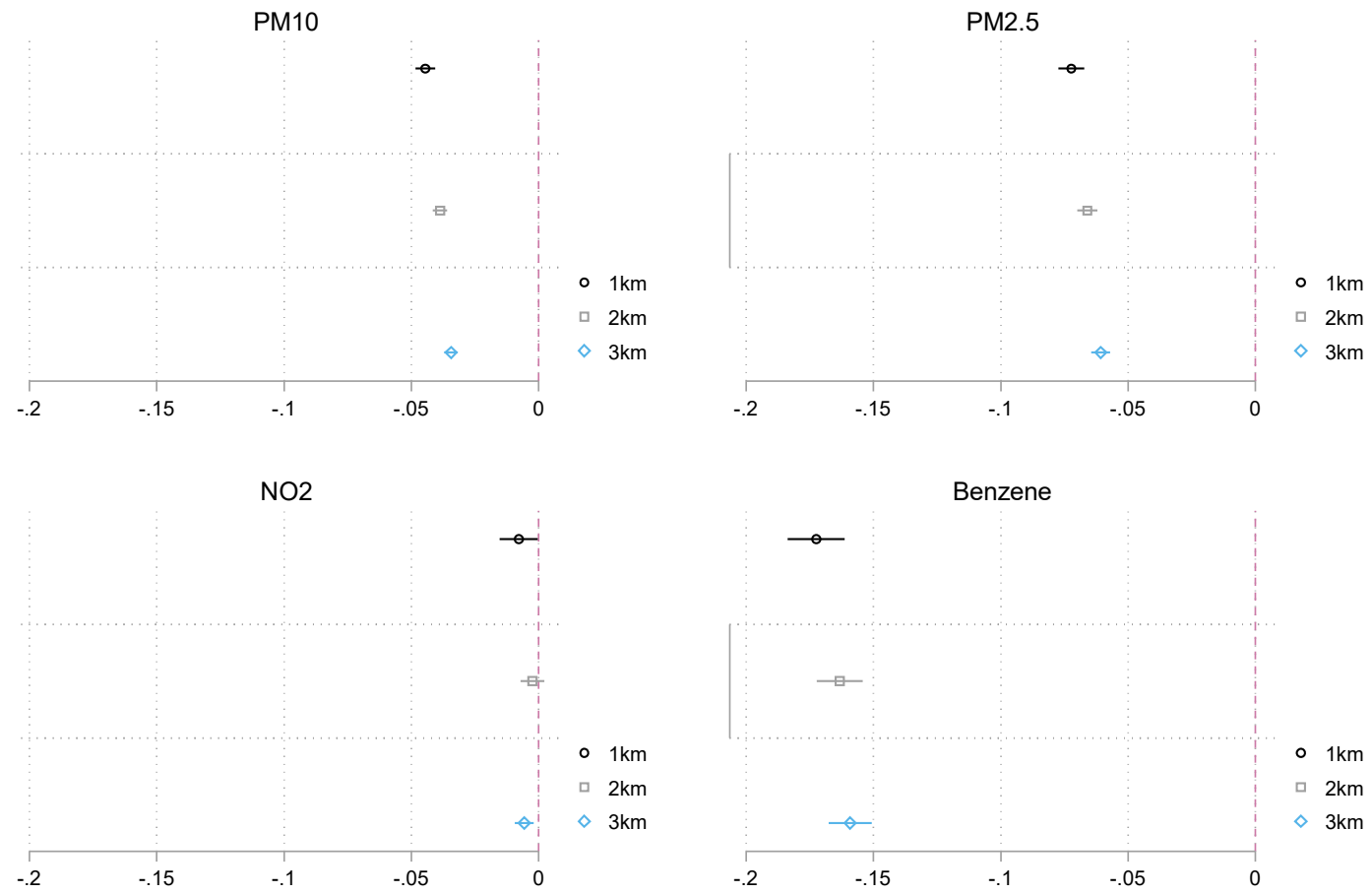

Note: Figure A3. displays the DiD estimates of equation (1) on air pollutants PM10, PM2.5, NO2 and Benzene, using as the treated group schools at $1 \mathrm{~km}, 2 \mathrm{~km}$ and $3 \mathrm{~km}$ from the CCZ.

Figure A4. Parallel Trends by School SES
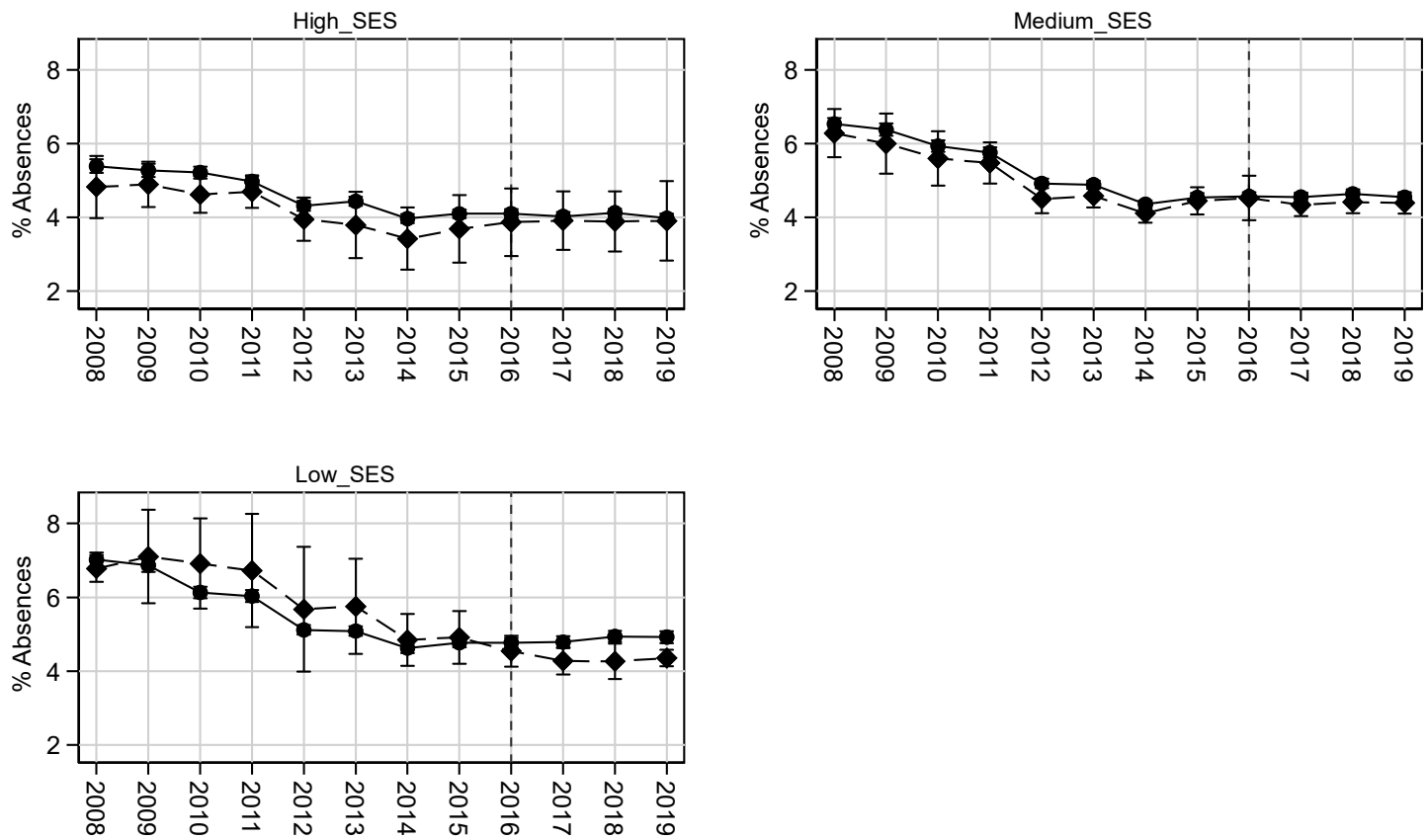

Note: The diamond shaped line represents schools in the CCZ and the dots schools outside the CCZ. 